\title{
Snake Antivenom, Anaphylaxis and Afterwards: Case Report
}

\author{
Duru M1, Sahan M1, Ozcan $0^{2}$, Karakus A ${ }^{1 *}$, Ozkan \\ $\mathbf{M}^{3}$ and Kuvandik $\mathbf{G}^{\mathbf{1}}$ \\ ${ }^{1}$ Department of Emergency Medicine, Mustafa Kemal \\ University, Hatay \\ ${ }^{2}$ Department of Biochemistry Mustafa Kemal University, \\ Hatay \\ ${ }^{3}$ Department of Plastic and Reconstructive Surgery \\ Mustafa Kemal University, Hatay \\ *Corresponding author: Ali Karakus, Emergency \\ Medicine Specialist, Mustafa Kemal University, Tayfur \\ Ata Sokmen of Medicine, Department of Emergency \\ Medicine, Hatay
}

Received: November 23, 2017; Accepted: December 14, 2017; Published: December 20, 2017

\begin{abstract}
Introduction: It is estimated that more than 2.5 million people are bitten by snakes each year, resulting in about 100,000 deaths and 400,000 amputations worldwide. Only about $15 \%$ of more than 3000 species of snakes are dangerous for human body.
\end{abstract}

Case Presentation: A 27-year old female patient was admitted in a local hospital after having been bitten on inner side of the thigh by a snake. This report describes a case of anaphylaxis resulting in necrosis after antivenom administration. The development of grade II and III envenomation needs a few hours. It has $10 \%$ risk of anaphylaxis with snake antivenom which is performed only for grade II or III envenomations.

Conclusion: Therefore snake antivenom treatment should be performed only in a well-equipped hospital and under specialist physician supervision. Otherwise the antivenom administration may lead to worse clinical complications than snake venom alone.

Keywords: Snake bite; Antivenom; Anaphylaxis

\section{Introduction}

It is estimated that more than 2.5 million people are bitten by snakes each year, resulting in about 100,000 deaths and 400,000 amputations [1]. Worldwide, only about $15 \%$ of the more than 3000 species of snakes are dangerous to human life [2]. In Turkey, 46 species of snake are present and 16 of them are considered venomous. Vipera ammodytes meridionalis and Vipera lebetina obtusa are the most common venomous snakes inflicting bites in the southern part of Turkey [3]. Snakebites can lead to different levels of toxicity, depending on several factors; snake species and size, amount of venom injected, location of bite, type and timing of medication and previous medical history of patient [2]. Envenomation due to snakebites may presented with different clinical manifestations including puncture wounds, pain, ecchymosis, lymphangitis, hemorrhagic bullae, necrosis, multiple organ failure and hemostatic disturbances [4]. Traditional management of snakebites consists of aggressive supportive care including analgesia, fluid replacement, antibiotic administration and extremity elevation. Antivenom therapy is the mainstay of this treatment. However, it has been previously reported that antivenom administration, a polyvalent immune FabAV, may lead to acute allergic reactions, with an incidence of approximately $<10 \%$ [5]. Anaphylaxis is a medical emergency requiring immediate diagnosis and treatment. It can be manifested by relatively minor signs and symptoms and may progress to a life-threatening respiratory and cardiovascular collapse. This report describes a case of anaphylaxis resulting in necrosis after antivenom administration.

\section{Case Presentation}

A 27-year old female patient was admitted in a local hospital after having been bitten on inner side of the thigh by a snake. Initially, the patient had normal vital signs except local swelling, tenderness and puncture marks on the bite region. After 1flacon antivenom (viper venom antiserum, Europan (equine) Institute of immunology, Zagrep, Croatia) was administered intramuscularly into the right gluteal muscles, then the patient was referred to our hospital since the local hospital was not well-equipped.

Seventy minutes after antivenom administration, the patient was admitted to our emergency department. Clinical examination revealed a lethargic patient with cool skin, blood pressure 60/40 $\mathrm{mmHg}$, heart rate $113 / \mathrm{min}$, and respiratory rate $24 / \mathrm{min}$. There was a hematoma measuring $8 \times 10 \mathrm{~cm}$ on inner side of the thigh with extensive soft tissue edema.

Laboratory investigation results were; blood glucose, 106 $\mathrm{mg} / \mathrm{dL} ; \mathrm{HCO}_{3}, 11.9 \mathrm{mEq} / \mathrm{L} ; \mathrm{pCO}_{2}, 26 \mathrm{mmHg} ; \mathrm{pO}_{2}, 103 \mathrm{mmHg}$; oxygen saturation $\left(\mathrm{saO}_{2}\right), 87 \%$. Other biochemical, hemogram and coagulation parameters were normal. In blood gas analyses, there was a lactic acidosis with high anion gap $(\mathrm{pH}, 7.16$; lactate, $6 \mathrm{mmol} / \mathrm{L}$; anion gap, 16.9).

Based on all these clinic and laboratory parameters, we considered that patient had an anaphylactic reaction to antivenom with grade I envenomation. The following treatment was given: oxygen through oronasal mask, $6 \mathrm{~L} / \mathrm{min}$; epinephrine $0.5 \mathrm{mg}$ was given intramuscularly and then $1 \mathrm{mg}$ epinephrine plus $100 \mathrm{cc}$ isotonic sodium clorur infused over one hour; fluid replacement therapy, isotonic sodium clorur $1000 \mathrm{cc}$ was given in $30 \mathrm{~min} .1$ ampoule antihistaminic (phenyramine maleate), 1 ampoule raniytidine and $80 \mathrm{mg}$ methylprednisolone were administered intravenously.

The patient was re-evaluated after first hour of treatment; blood pressure $90 / 60 \mathrm{mmHg}$, heart rate $123 / \mathrm{min}$, respiratory rate $20 / \mathrm{min}$ and $\mathrm{saO}_{2} 93 \%$. 


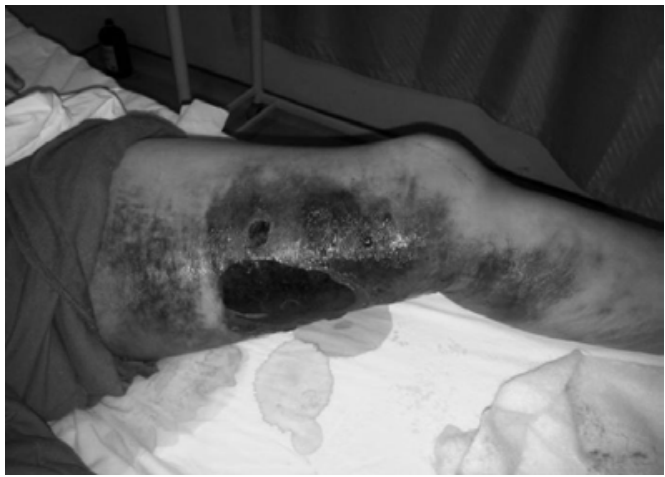

Figure 1: A necrotic lesion.

Subsequent maintenance therapy was given as follows: intravenous fluid replacement therapy at a dose of $40 \mathrm{cc} / \mathrm{kg}$, nasal oxygen $4 \mathrm{~L} / \mathrm{min}$, epinephrine infusion $1 \mu \mathrm{g} / \mathrm{min}, 3 \times 1$ ampoules of $20 \mathrm{mg}$ phenyraminemaleate, $4 \mathrm{x} 1$ ampoules of $50 \mathrm{mg}$ ranytidine, 1 ampoule of $80 \mathrm{mg}$ methylprednisolone, $2 \mathrm{x} 1$ ampoules of $1.2 \mathrm{~g}$ amoxicillineclavulanic acid for antibiotherapy and tramadol hydrochloride for pain control were administered intravenously and the patient was transferred to the intensive care unit. The patient's general condition and vital signs were remarkably improved within 24 hours. On the third day of hospitalization, a necrotic lesion measuring 20x15 cm was occurred at the bite region and the patient was transferred to the plastic surgery department for surgical operation (Figure 1). Before operation, 2 units of erythrocyte suspension because of a hemoglobin level of $7.8 \mathrm{gr} / \mathrm{dl}$. After three surgical debridements with an interval of three weeks and tissue grafting, the patient was discharged home in a good general condition on the $42^{\text {th }}$ day of admission.

\section{Discussion}

Snakebites are rarely seen in emergency departments but its prevalence is relatively higher in rural areas, particularly during the hot summer season, when snakes and victims are most active [6]. Venomous effects are the main determining factor and vary between snake species [7]. Venoms of Crotalidae and Viperidae snakes have more hemotoxic and necrotoxic properties [3]. In this case study, the snake was identified as a member of the viperidae family.

Snake venom has various toxic effects on the bitten region and on the whole body [8] including local pain and swelling at the bitten site, life-threatening disorders such as bleeding and coagulation disturbances, renal failure, and shock [9]. Applying an appropriate first aid and an effective treatment can decrease the mortality ratios. Therefore, the grade of the disease should be determined at first, and abnormal vital signs should be treated rapidly and the patient should be monitored for at least 12 hours at the emergency department [10].

Envenomation severity was clinically divided into four grade taking into consideration clinical symptoms and/or laboratory data as follows; grade 0 , dry bite with no envenomation and no symptoms or signs; grade 1, inflammatory edema within a few minutes, immediate pain at the bite site. Most envenomation stabilizes at grade 1 then regress spontaneously within $24-72 \mathrm{~h}$.; grade 2 , symptoms can develop either rapidly (early grade 2 ) with the appearance of hypotension in the first $30 \mathrm{~min}$ after snake biting or over a period of 6-16 h (classic grade 2) with extensive swelling, minimal systemic envenomation and laboratory findings and sometimes general symptoms and hemostatic disturbances; grade 3, symptoms can develop from progressive swelling including trunk to systemic symptoms, coagulopathy after grade 2 symptoms lasting for several hours $[11,12]$.

The most effective treatment of snakebites is the administration of antivenom promptly to the patient who has evidence of progressive signs and symptoms (grade 2 and 3). The antivenom binds and neutralizes the venom [6]. Removal of those toxins through the use of antivenom may facilitate a return to normal hemostasis. Of course, antivenom cannot repair injuries due to coagulopathy.

Antivenom contains heterologous proteins that monovalent horse antivenom is generally used to treat snake bite in Turkey and may cause acute allergic reactions with an incidence of approximately $<$ $10 \%$ [5]. Therefore, antivenom must be carefully administered under medical supervision [5]. A delay in clinical diagnosis and treatment of anaphylaxis may result in death by airway obstruction or vascular collapse. In literature, the mortality rate of $1 \%$ for anaphylaxis has been reported previously [13].

Similar snake species are encountered in southern part of our country. No mortality was reported in four study from this part of our country done by Zengin et al. (204 patients), Karakuş et al. (125 patients), Al et al. (79 patients) and Açıkalın et al. (45 patients) and all patients were followed at the hospital in these studies [14-16].

Antivenom administration may lead to serious anaphylactic reactions. Ayça et al reported that 34 patients out of 45 were treated with antivenom therapy and anaphylactic shock occurred in 8.9 percent of the patients [11]. In another study form Turkey, Karakus et al. reported that anaphylactic shock incidence in patients receiving antivenom therapy was 1.6 percent of all subjects $(n=125)$ [14]. All patients were treated in the hospital and no mortality was observed due to anaphylaxis in both studies. In the present case, based on all these clinic and laboratory parameters, we considered that patient had an anaphylactic reaction to antivenom with grade I envenomation.

As a conclusion, because of envenomation grade II and III take several hours to progress after snakebite, antivenom administration should be avoided in snake bites before although it has hemotoxic and necrotoxic properties. Antivenom treatment should be performed only in a well-equipped hospital and under specialist physician supervision. Otherwise the antivenom administration may lead to worse clinical complications than snake venom.

\section{References}

1. Williams D, Gutierrez JM, Harrison R, Warrell DA, White J, Winkel KD, et al. The Global Snake Bite Initiative: an antidote for snake bite. Lancet. 2010; 375: 89-91.

2. Gold BS, Dart RC, Barish RA. Bites of venomous snakes. N Engl J Med. 2002; 347: 347-356.

3. Baran I. Türkiye Amfibi ve Sürüngenleri. Tubitak Popüler Bilim Kitapları Başvuru Kitaplığı. Ankara. 2005.

4. Khimani A, Mcnierney A, Surani S, Surani S. Snake Envenomation Causing Distant Tracheal Myonecrosis. Case Reports in Pulmonology. 2013; 1: 3.

5. Ruha AM, Curry SC, Beuhler M, Katz K, Brooks DE, Graeme KA, et al. Initial post marketing experience with Crotalidae Polyvalent Immune Fab for treatment of rattlesnake envenomation. Ann Emerg Med. 2002; 39: 609-615. 
6. Duru M, Helvaci M, Peker E, Dolapcioglu K, Kaya E. Reptil bite in pregnancy. Hum Exp Toxicol. 2008; 27: 931-932.

7. Adukauskiene D, Varanauskiene E, Adukauskaite A. Venomous snakebites. Medicina. 2011; 47: 461-467.

8. Hall EL. Role of surgical intervention in the management of crotaline snake envenomation. Ann Emerg Med. 2001; 37: 175-180.

9. Juckett G, Hancox JG. Venomous snakebites in the United States: management review and update. Am Fam Physician. 2002; 65: 1367-1374.

10. Stewart CJ. Snake bite in Australia: first aid and envenomation management Accid Emerg Nurs. 2003; 11: 106-111.

11. Acikalin A, Gökel Y, Kuvandik G, Duru M, Köseoğlu Z, Satar S. The efficacy of low-dose antivenom therapy on morbidity and mortality in snakebite cases. Am J Emerg Med. 2008; 26: 402-407.
12. Haro L. Management of snakebites in France. Toxicon. 2012; 60: 712-718.

13. Kemp SF, Lockey RF. Anaphylaxis: a review of causes and mechanisms. J Allergy Clin Immunol. 2002; 110: 341-348.

14. Karakus A, Zeren C, Celik M, Arica S, Ozden R, Duru M, et al. 5-year retrospective evaluation of snakebite cases in Hatay, Turkey. Toxicology and Industrial Health. 2015; 31: 188-192.

15. Zengin S, Yılmaz M, Al B, Yildirim C, Yarbil P, Kilic H, et al. Plasma exchange as a complementary approach to snake bite treatment: An academic emergency department's experiences. Transfus Aphers Sci. 2013; 49: 494498

16. Al B, Orak M, Aldemir M, Güloğlu C. Snakebites in adults from the Diyarbakır region in southeast Turkey. Ulus Travma Acil Cerrahi Derg. 2010; 16: 210214.
Austin J Surg - Volume 4 Issue 4 - 2017

ISSN : 2381-9030 | www.austinpublishing group.com

Karakus et al. @ All rights are reserved
Citation: Duru M, Sahan M, Ozcan O, Karakus A, Ozkan M and Kuvandik G. Snake Antivenom, Anaphylaxis and Afterwards: Case Report. Austin J Surg. 2017; 4(4): 1112. 